\title{
Patient's Interest First
}

\author{
The Nature of Medical Ethics \\ and \\ The Dilemma of A Good Doctor
}


Published by

World Scientific Publishing Co. Pte. Ltd.

P O Box 128, Farrer Road, Singapore 912805

USA office: Suite 1B, 1060 Main Street, River Edge, NJ 07661

UK office: 57 Shelton Street, Covent Garden, London WC2H $9 H E$

and

Singapore University Press Pte Ltd

Yusof Ishak House, National University of Singapore

10 Kent Ridge Crescent, Singapore 119260

Patient's Interest First: The nature of medical ethics and the dilemma of a good doctor

Copyright $\odot 1998$ by World Scientific Publishing Co. Pte. Ltd.

\& Singapore University Press Pte Ltd

All rights reserved. This book, or parts thereof, may not be reproduced in any form or by any means, electronic or mechanical, including photocopying, recording or any information storage and retrieval system now known or to be invented, without written permission from the Publishers.

ISBN 981-02-3548-8

Printed in Singapore

by

Continental Press Pte Ltd

Office: 71 Ayer Rajab Crescent \#03-16, Ayer Rajah Industrial Estate, Singapore 139951 


\title{
Patient's Interest First
}

\author{
The Nature of Medical Ethics \\ and - \\ The Dilemma of A Good Doctor
}

by

Arthur S M Lim

Noworld Scientific Publishing Co Pte Ltd

Singapore $\bullet$ New Jersey $\bullet$ London • Hong Kong

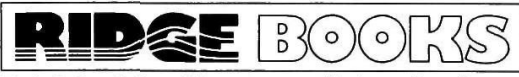

Published by Singapore University Press 
"I solemnly pledge to:

dedicate my life to the service of humanity;

give due respect and gratitude to my teachers;

practise my profession with conscience and dignity;

make the health of my patient my first consideration;

respect the secrets which are confided in me;

uphold the honour and noble traditions of the medical profession;

respect my colleagues as my professional brothers and sisters;

not allow the considerations of race, religion, nationality or social standing to intervene between my duty and my patient;

maintain due respect for human life;

use my medical knowledge in accordance with the laws of humanity; comply with the provisions of the Ethical Code; and constantly strive to add to my knowledge and skill.

I make these promises solemnly, freely and upon my honour."

The Singapore Medical Council Pbysician's Pledge 


\title{
Contributors
}

\author{
Doctor Vivian Balakrishnan \\ M Med(Ophth), FRCSE, FRCOphth
}

Dr Balakrishnan is the Deputy Medical Director of the Singapore National Eye Centre; Dept Director, Dept of Ophthalmology, National University Hospital; Consultant \& Clinical Head, Paediatric Ophthalmology Service, KK Women's \& Children's Hospital; Senior Lecturer, Dept of Ophthalmology, National University of Singapore; and a council member of the Singapore Medical Association. Chapter VII

\section{Doctor Gwee Ah Leng \\ M D, FRCP}

Dr Gwee was the former Senior Physician, Dept of Clinical Medicine, University of Singapore; former President of the Singapore Medical Council; former President of the Singapore Medical Association; and a leading thinker on medical ethics Chapters I and II

\section{Doctor Khoo Chong Yew}

PBM, MB BCh, FAMS, FRCSE, FRACS, FRCOphth, DO

Dr Khoo is the Founder Chairman of the Ethics Committee in the Gleneagles Hospital and the Singapore National Eye Centre; member of the Complaints Committee of the Singapore Medical Council; member of the National Committee of Ophthalmology in charge of ethics; and member of the Inquiry Panel of the Singapore Law Society. He was the President of the Singapore Medical Association.

\section{Chapter VIII}

\section{Professor Arthur SM Lim}

BBM, MBBS, FAMS, FRCS, FRCSE, FRACS, FICS(Hon), FRACO, FRCOphth, DO

Professor Arthur Lim is the Clinical Professor and Head, Dept of Ophthalmology, National University of Singapore; Medical Director of the Singapore National Eye Centre; past President of the Singapore Medical Association; and a former member of the Singapore Medical Council. Amongst the appointments which Professor Lim holds on the international level, he is the Second Vice-President of the distinguished Academia

Ophthalmologica Internationalis, the council responsible for the promotion of medical ethics in global ophthalmology.

Chapters I, II, III, IV, V, VI, VII \& VIII.

\section{Editor}

\section{Dr Janadas Devan \\ $\mathrm{PhD} \mathrm{MA}, \mathrm{BA}(\mathrm{HON})$}

Dr Janadas Devan has published and translated numerous books and written reviews and articles on politics and culture in Singapore, Malaysia and India. His work has appeared in The Hindu, Indian Financial Express, Straits Times (Singapore), Business Times (Singapore), MR (Malaysia). 


\section{Contents}

Preface

Chapter I Some Concepts on Medical Ethics

What is Ethics - The Ethical Code in Medical Regulation - Expectations of The Community - Society's Needs - Conflicts - Conclusion

Chapter II

Some Controversies of Medical Ethics

Interests of the Patient or Community - Technology and Cost - Doctors in Court - Professional Confidentiality - Learning Curve and Patient's Best Interest - Patient's Desire Versus Medical Scientific Advances Advertisements - Sanctity of Life and Technology - Training and the Problem of Self-Interest - Teaching Medical Ethics or Punishment Ethics and Discipline - Conclusion

The Good Doctor and Excellence in Medicine

Patients' Interest Foremost - 'Do No Harm' - The Good Doctor Changes in Medicine - What of Singapore - Excellence - Strength of Character - Monetary Gain is Secondary - Establish Healthy Relationships - Conclusion

Ethics, the Profession and the Nation

Obstacles - Ethics and Profession - The Medical Profession and The Nation - What of Medicine - Manpower - The Future - Conclusion

Right to Information

What Do We Need to Tell Our Patients - Informed Consent for Clinical Trials - Qualifications of Doctors - Good Medical Records Conclusion

Chapter VI Limits to Freedom and Ethics in Medicine: the Patient or the State?

Internal Constraints: Professional Oaths and Codes - External Constraints: Courts of Law - External Constraints: The Economics of Health Care - External Constraints: Government - Conclusion A Game of Chess 
Chapter VII Quality of Life and the Right to Live (by Dr Vivian Balakrishnan)

Quality is Relative - Who Decides - Decision Making - What is the Definition of Terminal Illness - The Experimental Form of Treatment - Should We Legalize Euthanasia - What About Pain and Suffering Specific Legislation to Govern Perimortal Decisions - Conclusion

Chapter VIII Promoting Ethics (by Dr Khoo Chong Yew)

Growing Patients Expectations - The Effect of Medico-legal Suits on Doctors - The Doctor's New Roles - The Effects of High Technology - Communication Skills Training - At the National Level - Codes of Ethics - At the University Level - At The Hospital Level - At The Doctor Level - Defensive Medicine - The Golden Rule - The Image of The Doctor - At the Patient Level - Conclusion

In Search of Success

A - Codes of Ethics

A1.1 Commonwealth Medical Association (CMA) Ethical Code - A1.2 The Declaration of Helsinki 1964 - A1.3 The International Code of Ethics - A1.4 The Declaration of Geneva - A1.5 The Hippocratic Oath - A1.6 The General Medical Council of United Kingdom's Code of Professional Conduct and Discipline: Fitness to Practice - A1.7 The Singapore Medical Council's Ethical Code - A1.8 The Singapore Medical Association Medical Code

B - List of Articles

B1.1 Patients' Interests Must Be Top Priority - B1.2 Doctors Urged To Revise Ethics Codes \& Introduce Instruction On Medical Ethics At University - B1.3 Important To Teach Medical Ethics To Undergraduates - B1.4 Over 100 New Doctors Take Oath For First Time Here - B1.5 Do Not Be Too Harsh On Doctors Who Make Mistakes - B1.6 The Hopeless Problem Of The Chronic Sick - B1.7 You And Your Doctor-A Question Of Ethics 


\section{Preface}

When major changes in medical practice escalates in the twenty-first century, ethical problems will become the dilemma of doctors. If we can embrace these changes and influence ethics, by always placing patient's interest first, it may be possible to show the world once more that doctoring has always been the noblest of the professions.

Many of the challenges of medical ethics did not exist when Hippocrates wrote his famous oath. The medical demands of the twenty-first century will include numerous ơnew problems of quality care, increasing patient demand, the impact of high technology, othe definition of death and controversies regarding the right to live and the right to die. IIn addition, there will be questions raised by research on embryos, new approaches to 要, Fenetics, the ethics of experiments on animals and clinical trials, and the problems of olimited medical resources. These will lead to grave dilemmas causing uncertainty and 递

These changes - combined with increasing health costs running into billions per annum - will force governments, politicians and administrators to impose their Ewill on the medical profession. I believe that this will lead to a revolution in medical thinking and ethics.

I owe a great deal to Dr Gwee Ah Leng for much of my thinking on medical ethics. As a young doctor, I used to immerse myself regularly in deep discussions, both assisting and learning from him, as he delved into medical ethics some 20 to 30 years ago.

This publication contains lectures, thoughts and essays on medical ethics by $\mathrm{Dr}$ ¿ Gwee Ah Leng and a number of leading Singapore doctors like the late Dr Tan Joo $\underset{+}{+}$ Seng and Dr B.R. Sreenivasan. It is useful to record the ethical concepts of our leaders $\rightarrow$ in medicine - despite the disadvantages of overlapping ideas, and disagreements in f thinking. In fact, controversies on medical ethics is essential for progress in a world $\vec{s}$ that has rapidly changing values.

Let us also look at some of the issues that will be discussed:

Chapter I and II are based on Dr Gwee Ah Leng's thoughts, his private papers on ethics, and his discussions with me. 
Chapter III evolved from a 1996 address I delivered to medical undergraduates at their annual dinner and Chapter IV emphasizes the importance of ethics and how it relates to the nation. The material is based on my Singapore Medical Association lecture.

Chapter V explains the need for better communication between doctors and their patients, and the increasing public demand for information throughout Asia. I remember once, when a representative of the Singapore Medical Association was required to speak to a thousand people. No doctor wanted to and I had to volunteer. As it turned out, the first questions were quite aggressive.

One of the questions asked was, "If I have already paid $\$ 60$ for a consultation, why must I pay the doctor more money when I ask for a medical report a year later? Is the doctor exploiting me?"

It was explained that a medical report incurs administrative costs. A filing clerk has to retrieve the case notes. After the facts are verified, the doctor dictates the report. A medical secretary types the letter for the doctor to sign. It is then posted.

Chapter VI deals with limits to a doctors' freedom to treat patients as individuals. Doctors also have a duty to our rapidly changing society. Many non-medical influences like economic development, public demand, high technology, manufacturers, medical insurers, hospital administrators, and politicians have an impact on the profession. All this has led to upward spiraled healthcare costs that run into billions of dollars. Our society is also becoming increasingly litigious. Patients are demanding that their 'rights' be acceded to.

Chapter VII by Dr Vivian Balakrishnan, deals with the quality of life and the right to live. The last few years have seen the rapid development of high-technology medicine. On one hand, this has allowed doctors to help prolong life. On the other, it has introduced controversial ethical issues.

Chapter VIII deals with the future of medical ethics by Dr Khoo Chong Yew, who has been promoting ethics for two decades. Dr Khoo was also the President of the Singapore Medical Association, and a member of the Singapore Medical Council. 